\title{
Determination of in vitro Antioxidant and Radical Scavenging Activities of Different Extracts of Allium sativum (Garlic)
}

\author{
*Dandare, S. U ${ }^{1}$, Ezeonwumelu, I. J ${ }^{2}$, Ezeh, C. $\mathrm{P}^{2}$ and Auta, $\mathrm{H}^{3}$ \\ ${ }^{1}$ Department of Biochemistry, Usmanu Danfodiyo University, Sokoto, Nigeria. \\ ${ }^{2}$ Department of Applied Biochemistry, Nnamdi Azikiwe University, Awka, Nigeria. \\ ${ }^{3}$ Department of Biochemical Engineering, University College London, United Kingdom.
}

\begin{abstract}
Allium sativum (Garlic) is indigenous to Asia, but largely cultivated in Nigeria. It has acquired a reputation in folklore as a formidable prophylactic and therapeutic agent. This study was undertaken to evaluate the in vitro antioxidant activity of three extracts [ aqueous (AE), ethyl acetate (EA) and petroleum ether (PE)] of garlic using two antioxidant tests; ferric ion reducing power and $\mathrm{H}_{2} \mathrm{O}_{2}$ scavenging capacity. The reductive power of each extract was found to be directly proportional to its concentration $(0.2 \mathrm{mg} / \mathrm{ml}-1 \mathrm{mg} / \mathrm{ml})$ which followed the pattern $A E>E A>P E$ showing the strongest to the least strong antioxidant activity. The reductive power of ascorbic acid as the standard was compared with those of the extracts and was found to be significantly higher $(p<0.05)$ at all concentrations except $0.6 \mathrm{mg} / \mathrm{ml}$ of the aqueous extract. Similarly, ascorbic acid showed strong $\mathrm{H}_{2} \mathrm{O}_{2}$ scavenging activity when compared to the extracts $(p<0.05)$. The $\% \mathrm{H}_{2} \mathrm{O}_{2}$ inhibition ranged from 67-73, 40-50 and 25-35 for AE, EA and PE extracts respectively. Furthermore, the extracts demonstrated high antioxidant activity against hydrolytic rancidity of crude palm oil by virtue of the low acid value they showed in a concentration dependent manner. The acid values ranged from 4.74 through $5.50 \mathrm{viz}$. ascorbic acid $<A E<P E<E A$. These results indicate that garlic prevents lipid peroxidation and radicalic chain reactions. At the same time, the aqueous extract revealed more effective antioxidant capacity than the EA and PE extracts, hence this encourages the culinary use of garlic.
\end{abstract}

Keywords: Allium sativum, antioxidant activity, radical scavenging, acid value, in vitro.

\section{Introduction}

There has been an upsurge of interest in the therapeutic potential of medicinal plants as antioxidants with the capacity of reducing free radicals induced damages rather than looking for synthetic ones. Epidemiological studies have shown that diets rich in fruits, herbs and spices are associated with a low risk of many diseases (McClements and Decker, 2000). Garlic (Allium sativum L.) is one of the most popular medicinal agents in the world particularly in Asia. As a prophylactic and a therapeutic agent, it elicits inhibition against hypertension (Krishnaragu et al., 2006), steatohepatitis (Sang et al., 1995), drug-induced nephrotoxicity (Abdelaziz and Kandeel, 2011), Helicopter pylori associated gastric cancer (Adeniyi et al., 2006), diabetes mellitus, cardiovascular diseases (Banerjee and Maulik, 2002), angiogenesis, metastasis and cancer (Morihara, 2010). Studies have also proved it to be antifungal (Davis, 2005), anthelminthic (Singh et al., 2009) and antibacterial (Khadri et al., 2010). Conversely, some studies have also reported of its adverse and toxic effects (Banerjee and Maulik, 2002). All these therapeutic effects of Allium sativum are due to its bioactive components which include; organosulphur compounds (allicin, diallyl disulphide and diallyl trisulphide), dietary fibre, microelements (Selenium) and polyphenols (flavonoids) (Gorinstein et al., 2005).

Nevertheless, the organosulphur compounds with their derivatives and the polyphenols are mainly responsible for its antioxidant activity either directly as an antioxidant or indirectly by modulating the proapoptotic pathway (Kelsey et al., 2010) or activating the endogenous antioxidant system, involving gene targets of the Nrf2/ARE transcription factor pathway required for the synthesis of endogenous antioxidants (Capasso, 2013). However, in the event of antioxidant deficiency or an imbalance due to UV radiation, smoking, drug abuse, etc (Capasso, 2013), the cellular levels of the free radicals rise such that the endogenous antioxidants are no longer able to mop them, thus, the excess free radicals move to self-stabilize by oxidizing other molecules within its vicinity resulting to a DNA, protein or lipid damage (Kelsey et al., 2010). Exogenous antioxidants with effect are widely studied as they have shown significant therapeutic effect on the oxidant-induced diseases by providing adequate reinforcement to the overwhelmed endogenous antioxidants (Leonard et al., 2002).

Further, the free fatty acid (FFA) and Acid value of any lipid are both measures of hydrolytic rancidity, where lower values corresponds to slower rates of hydrolytic rancidity (Ihekoronye and Ngoddy, 1985). In order to prolong the shelf life of vegetable oils there is the need to protect these oils from hydrolytic rancidity. The use of synthetic antioxidants such as Butylatedhydroxylanisole (BHA), Butylatedhydroxyl toluene (BHT), Propylgallate (PG) and Citric acid to prevent lipid oxidation have been established (Ruger et al., 2002; Ullah et al., 2003). However, some of these antioxidants especially BHT and BHA are carcinogenic thus, there use as 
food additives in international market is highly discouraged (Carrasquero et al., 1998). Hence, there is a great need to exploit naturally derived antioxidants from plants to substitute these synthetic antioxidants.

The antioxidant activity of Allium sativum, depends largely on the analytical system, purity of the bioactive compounds, extraction method and the polarity of the extracting solvent (Sagar and Singh, 2011). This study was therefore aimed at evaluating the antioxidant activity of different extracts (Aqueous, petroleum ether, and ethyl acetate) of Allium sativum.

\section{Plant material:}

\section{Materials And Methods}

Allium sativum cloves were obtained from Sokoto, Nigeria. The botanical identity of the sample was further confirmed at the Herbarium section of the Botany unit of Department of Biological Sciences, Usmanu Danfodiyo University, Sokoto.

\section{Preparation of extracts:}

The transparent coverings were removed and the cloves were washed and ground in mortar and pestle. The resulting paste was then dried under the shade and subsequently ground into fine powder which was stored in air tight container until needed for experiment.

$100 \mathrm{~g}$ of the powdered sample was soaked in $500 \mathrm{ml}$ of $95 \%$ ethanol for $24 \mathrm{hrs}$. The mixture was later filtered using a Whatman no.1 filter paper and the filtrate was evaporated in a drying cabinet at $45^{\circ} \mathrm{C}$ for $72 \mathrm{hrs}$. The yield was $9.67 \mathrm{~g}$. The residue $(9.67 \mathrm{~g})$ was dissolved in $200 \mathrm{ml}$ deionized water and successively extracted with petroleum ether and ethyl acetate solvents. The petroleum ether, ethyl acetate and water fractions yields after evaporation were $0.4 \mathrm{~g}, 2.7 \mathrm{~g}$, and $2.9 \mathrm{~g}$ respectively. These residues were screened for their antioxidant activity.

\section{Ferric ion reducing power:}

The method described by Oyaizu (1986) was used to determine the reducing power of the extracts. Briefly, $1.0 \mathrm{ml}$ of the extracts and ascorbic acid (Standard) were prepared in distilled water. Varying concentrations $(0.2-1.0 \mathrm{mg} / \mathrm{ml})$ were mixed individually with $0.5 \mathrm{ml}$ of $0.2 \mathrm{M}$ phosphate buffer $(\mathrm{pH} 6.6)$ and 0.5 $\mathrm{ml}$ potassium ferricyanide $(1 \% \mathrm{w} / \mathrm{v})$. The resulting mixtures were incubated at $50{ }^{\circ} \mathrm{C}$ for 20 min and $2.5 \mathrm{ml}$ of $10 \%$ trichloroacetic acid added to each of them. The entire mixture was centrifuged at $3000 \mathrm{rpm}$ for $10 \mathrm{~min}$ and $2.5 \mathrm{ml}$ of the supernatant was mixed with $2.5 \mathrm{ml}$ of distilled water, $0.5 \mathrm{ml}$ of ferric chloride $(0.1 \%)$ was added, and the absorbance read at $700 \mathrm{~nm}$.

\section{Hydrogen peroxide scavenging activity:}

The ability of the extracts to scavenge hydrogen peroxide was determined according to the method of Ruch et al., (1989). A solution of hydrogen peroxide (40mM) was prepared in phosphate buffer ( $\mathrm{pH} 7.4)$. Hydrogen peroxide concentration was determined spectrophotometrically at $230 \mathrm{~nm}$. Sample extracts and standard $(0.2-1.0 \mathrm{mg} / \mathrm{ml})$ was added to a hydrogen peroxide solution $(0.6 \mathrm{ml}, 40 \mathrm{mM})$. Absorbance at $230 \mathrm{~nm}$ was determined after 10 mins against a blank solution containing phosphate buffer without hydrogen peroxide.

The percentage of hydrogen peroxide inhibition was calculated:

$\%\left[\mathrm{H}_{2} \mathrm{O}_{2}\right]$ inhibition $\left.=\left(\mathrm{A}_{0}-\mathrm{A}_{1}\right) / \mathrm{A}_{0}\right) 100$

where $\mathrm{A}_{0}$ was the absorbance of the control, and $\mathrm{A}_{1}$ was the absorbance of the extracts and standard.

\section{Acid value determination:}

The titrimetric method (1987) was employed. $5 \mathrm{~g}$ of the palm oil was weighed in $250 \mathrm{ml}$ conical flask and $50 \mathrm{ml}$ ethanol was added and shaked vigorously. Then 2 drops of phenolphthalein were added as indicator and titration was carried out against $0.25 \mathrm{~N} \mathrm{NaOH}$ with vigorous shaking after each addition till a permanent light pink colour was produced which persist for at least one minute. Acid value was calculated using the following formula:

$\%$ free fatty acid/Acid value $=(100 / \mathrm{W}) \times(282 / 4) \times(\mathrm{V} / 1000)$

Where, $\mathrm{W}$ is the weight of oil, $\mathrm{V}$ is the volume of $0.25 \mathrm{NaOH}, 282$ is the known equivalent weight of oleic acid.

\section{Statistical Analysis:}

All values were expressed as mean \pm S.D. and one way ANOVA was done to analyze significant difference using the statistical analysis software package SPSS (version 16.0). Values with $\mathrm{p}<0.05$ were considered as significant 


\section{Results}

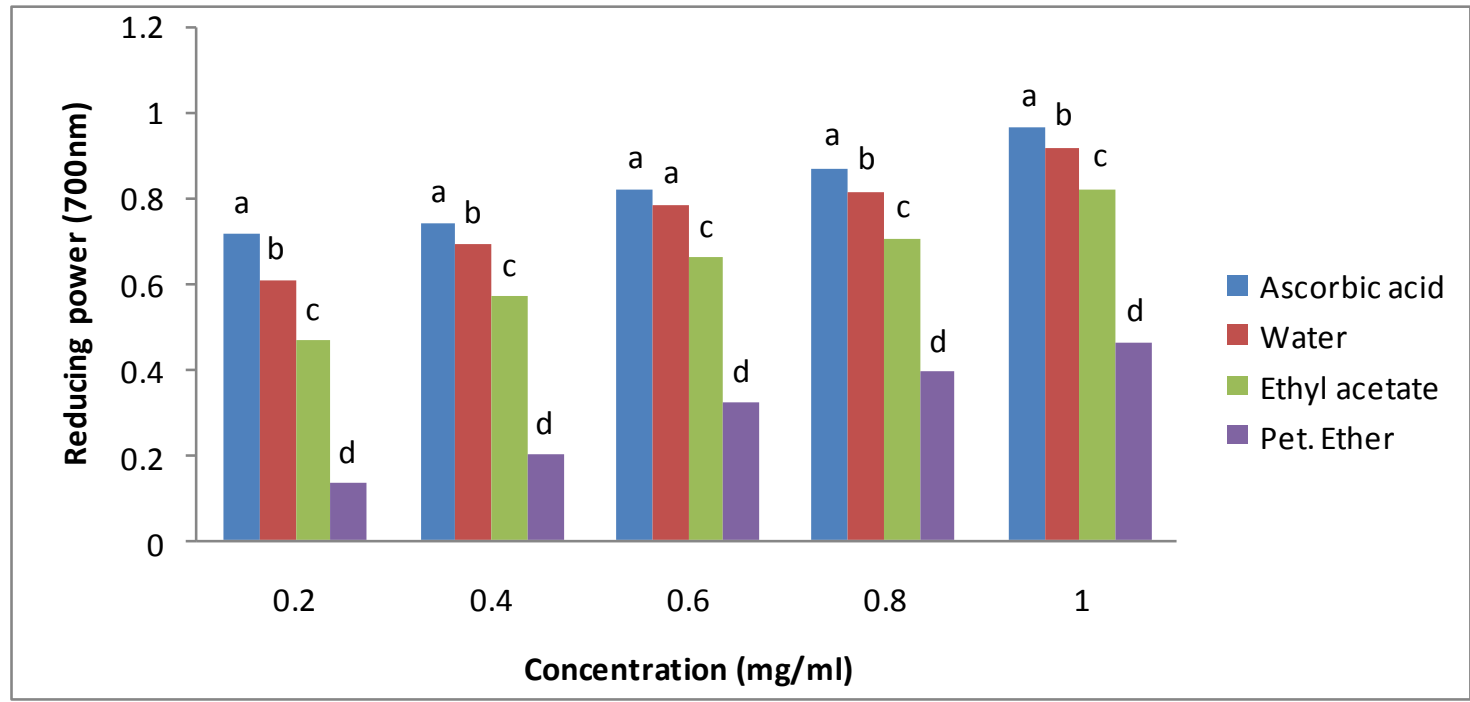

Figure 1: Ferric ion reducing power of ascorbic acid, aqueous, ethyl acetate and petroleum ether extracts of Allium sativum. Values represent means \pm SD of triplicate measurement. Bars on the same group, carrying different letters $(\mathrm{a}-\mathrm{d})$ are significantly different $(\mathrm{P}<0.05)$.

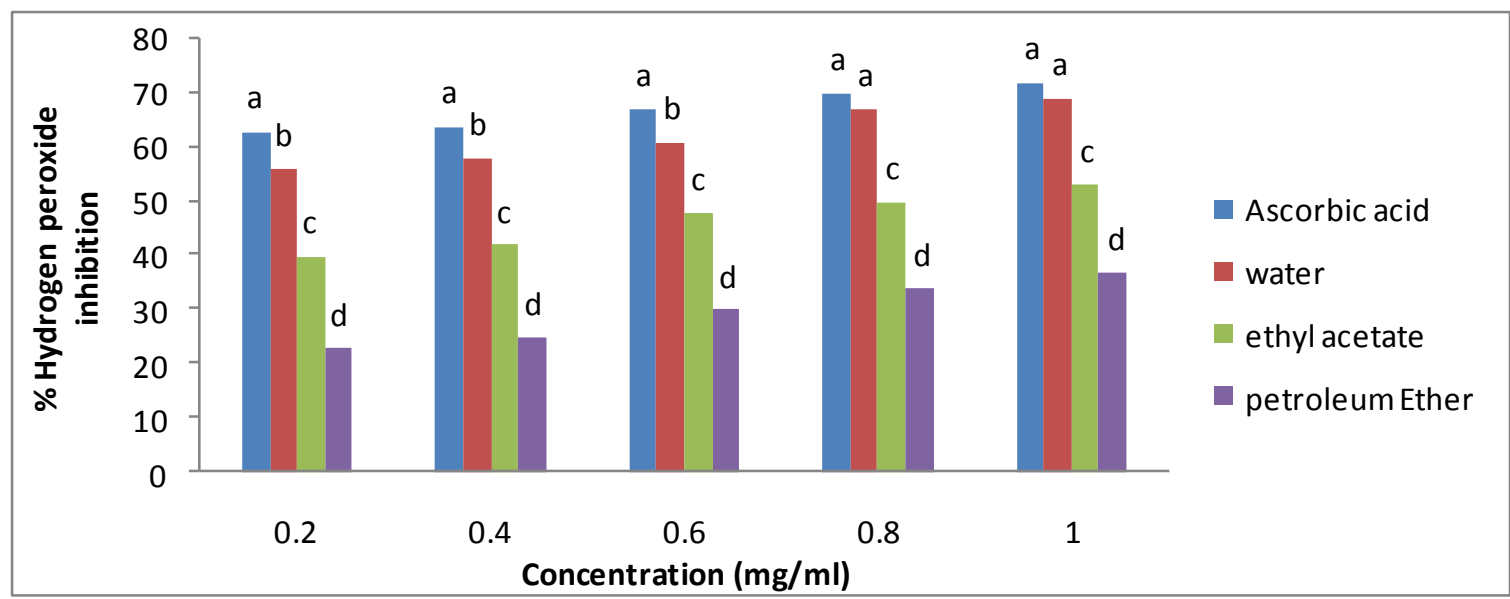

Figure 2: Percentage hydrogen peroxide inhibition of ascorbic acid, aqueous, ethyl acetate and petroleum ether extracts. Values represent means \pm SD of triplicate measurement. Bars on the same group, carrying different letters $(\mathrm{a}-\mathrm{d})$ are significantly different $(\mathrm{P}<0.05)$.

Table 1: The effect of ethyl acetate, petroleum ether, aqueous extracts of Allium sativum and ascorbic acid on the acid value of stored palm oil (1-3 weeks)

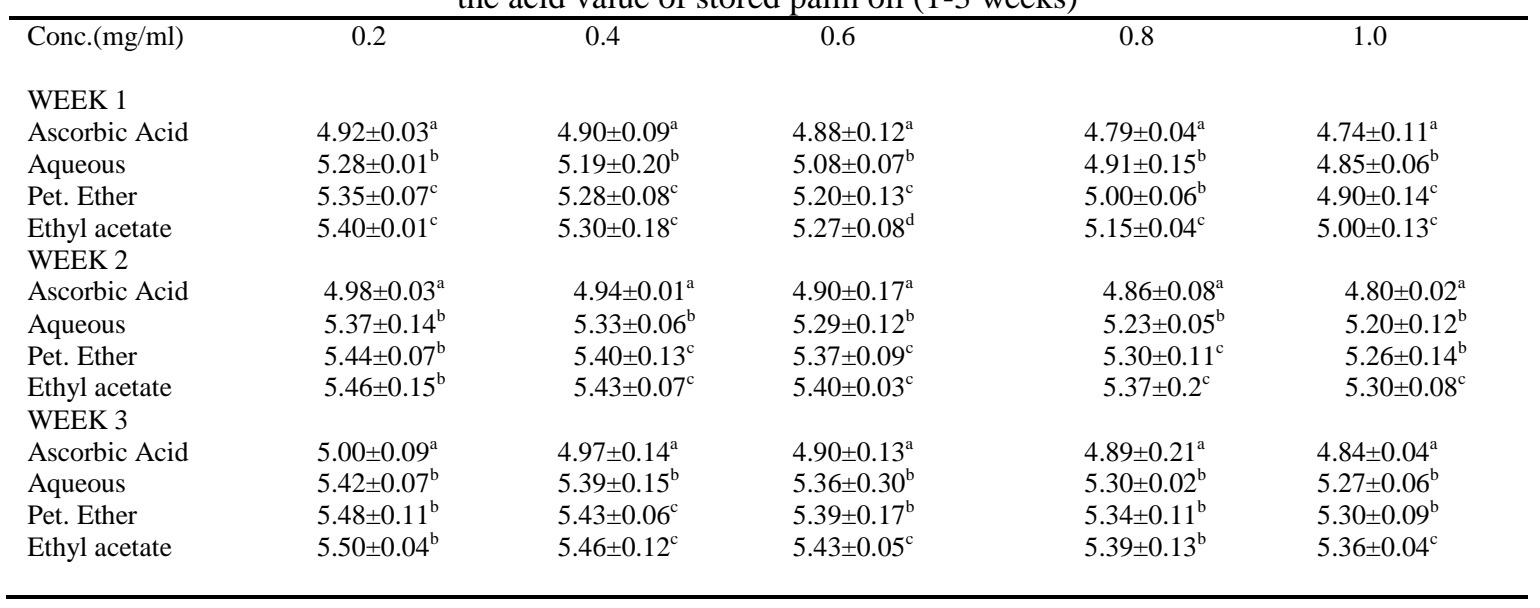


Values represent mean $\pm \mathrm{SD}$ of triplicate measurement $(\mathrm{n}=3)$. Values along the same column and row with different superscripts are significantly different $(\mathrm{P}<0.05)$.

\section{Discussion}

The activities of the antioxidants have been ascribed to various mechanisms such as, the prevention of chain initiation, decomposition of peroxides, reducing capacity and radical scavenging (Yildrim et al., 2000). It is an established phenomenon that reducing power is linked strongly with antioxidant potential and it correlates with the phenolic constituents in various vegetables/foods. Hence, the reducing power of a compound may serve as an important marker of its possible antioxidant activity. In this study, the reductive power of each extract increased in a concentration dependent pattern from $0.2 \mathrm{mg} / \mathrm{ml}$ up to $1 \mathrm{mg} / \mathrm{ml}$, with the aqueous extract (AE) having the strongest antioxidant activity, followed by the ethyl acetate (EA) and petroleum ether (PE) extracts in that order. Comparison of the reducing power activity of ascorbic acid and AE showed that ascorbic acid activity was higher $(\mathrm{p}<0.05)$ than that of AE at all concentrations except at $0.6 \mathrm{mg} / \mathrm{ml}$ concentration (Fig. 1 ). This supports previous report by Panpatil et al., (2013), that the antioxidant activity of Allium sativum and ascorbic acid are comparable. Studies have shown that aqueous extract of Garlic has a higher antioxidant potential and total phenolic content (TPC) than other organic solvent extracts (Gorinstein et al., 2006; Wangcharoen and Morasuk, 2007). This is because about $97 \%$ of the bioactive components of Allium sativum have been found to be water-soluble (Koch and Lawson, 1996).

Hydrogen peroxide scavenging activity method is generally applied in determining the potential of free radical elimination. Ascorbic acid had strong $\mathrm{H}_{2} \mathrm{O}_{2}$ scavenging activity when compared to the extracts $(\mathrm{P}<$ 0.05). In the present study the percentage $\mathrm{H}_{2} \mathrm{O}_{2}$ inhibition ranged from 67-73, 40-50 and 23-35 for AE, EA and $\mathrm{PE}$ respectively. Conversely, lower free radical scavenging have been reported using different vegetative parts of Allium sativum; DPPH scavenging activity ranged from 3.60\% to $45.63 \%$ for garlic bulbs (Chen et al., 2013), $66.48 \%$ in the leaves of A. sativum L. and in fried garlic (60.85\%) (Queiroz et al., 2009).

A possible mechanism of decreasing oxidative damage in cells by garlic extracts is by preventing lipid peroxidation (Fenercioglu et al., 2010). In the present study, the extracts demonstrated a high antioxidant activity against hydrolytic rancidity of crude palm oil in a concentration dependent manner. Similarly, Leelarungrayub et al., (2006) reported that fresh garlic preparations inhibited lipid oxidation and accelerated their decomposition but had no effect on protein oxidation. Comparison of the antioxidant activity of the extracts on the hydrolytic rancidity of palm oil showed that the acid value increased with prolonged storage. Here, the lowest acid value at the end of the third week at $1 \mathrm{mg} / \mathrm{ml}$ of the extracts corresponds to the acid values of the first week at $0.6 \mathrm{mg} / \mathrm{ml}, 0.4 \mathrm{mg} / \mathrm{ml}, 0.2 \mathrm{mg} / \mathrm{ml}$ and $0.2 \mathrm{mg} / \mathrm{ml}$ of extracts for Ascorbic acid, PE, AE and EA respectively. The observed trend implies that there exists a negative correlation between storage and antioxidant activity i.e. the antioxidant activity of Allium sativum decreases with prolonged storage.

\section{Conclusion}

The present investigation shows that Allium sativum has antioxidant properties by virtue of its ability to serve as a reducing agent, free radical scavenger and also decrease lipid peroxidation. Amongst all the solvent extracts of Allium sativum, the aqueous extract possessed the greatest antioxidant activity. Thus, this encourages the culinary use of garlic and potential exploitation for the treatment of radicals/disease induced oxidative stress.

\section{References}

[1]. Abdelaziz, I. and Kandeel, M., 2011. The Protective Effect of Nigella sativaOil and Allium sativum Extracts on Amikacin-Induced Nephrotoxicity. .International Journal of Pharmacology., 7(6):697-703.

[2]. Adeniyi, B. A., Oluwole, F. S. and Anyiam, F. M., 2006. Antimicrobial and Antiulcer Activities of Methanol Extract of Allium sativumon Helicobacter pylori. Journal of Biological Sciences., 6(3):521-526.

[3]. Banerjee, S. K., Maulik, M., Mancahanda, S. C., Dinda, A. K., Gupta, S. K. and Maulik, S. K., 2002. Dose-dependent induction of endogenous antioxidants in rat heart by chronic administration of garlic. Life Sci., 70:1509-1518.

[4]. Capasso, A., 2013. Antioxidant Action and Therapeutic Efficacy of Allium sativum L. Molecules. 18:690-700. doi:10.3390/molecules 18010690

[5]. Carrasquero, A., Salazar, M. and Nava, P. B., 1998. Antioxidant activity of grape seed extract on vegetable oils, J. Sci. Food \& Agric., 77:436-467.

[6]. Chen, S., Shen, X., Cheng, S., Li, P., Du, J., Chang, Y. and Meng, H., 2013. Evaluation of Garlic Cultivars for Polyphenolic Content and Antioxidant Properties. PLoS ONE., 8(11): e79730. doi:10.1371/journal.pone.0079730.

[7]. Davis, S. R., 2011. An Overview of the Antifungal Properties of Allicin and its Breakdown Products- the Possibility of a Safe and Effective Antifungal Prophylactic. Mycoses., 48:95-100

[8]. Fenercioglu, A.K., Saler, T., Genc, E., Sabuncu, H., Altuntas, Y., 2010. The effects of polyphenol-containing antioxidants on oxidative stress and lipid peroxidation in Type 2 diabetes mellitus without complications. J Endocrinol Invest., 33(2):118-24.

[9]. Gorinstein, S., Drzewiecki, J., Leontowicz, H., Leontowicz, M., Najman, K., Jastrzebski, Z., Zachwieja, Z., Barton, H., Shtabsky, B., Katrich, E., et al., 2005. Comparison of the bioactive compounds and antioxidant potentials of fresh and cooked Polish, Ukrainian and Israeli garlic. J. Agric. Food Chem., 53: 2726-2732. 
[10]. Gorinstein, S., Leontowicz, H., Leontowicz, M., Drzewiecki, J., Najman, K., Katrich, E., Barasch, D., Yamamoto, K. and Trakhtenberg, S., 2006. Raw and boiled garlic enhances plasma antioxidant activity and improves plasma lipid metabolism in cholesterol fed-rats. Life Sci., 78: 655-663.

[11]. Ihekoronye, A.I. and Ngoddy, P.O., 1985. Integrated Food Science and Technology for the Tropics, Macmillian Publisher Limited, London, 67-78.

[12]. Kelsey, N. A., Wilkins, H. M. and Linseman, D. D., 2010. Nutraceutical Antioxidants as Novel Neuroprotective Agents. Molecules., 18:7792-7814.

[13]. Khadri, S., Boutefnouchet, N. and Dekhil, M., 2010. Antibacterial Activity Evaluation of Allium sativum Essential Oil Compared to Different Pseudomonas Aeruginosa Strains in EasternAlgeria. Chemistry \& Chemical Engineering, Biotechnology, Food Industry., $11(4): 421-428$

[14]. Koch, H.P. and Lawson, L.D., 1996. Garlic: The Science and Therapeutic Application of Allium sativum L. and Related Species, 2nd Edn., Williams \& Wilkins, Baltimore,

[15]. Krishnaraju, A.V., Rao, T. V. N., Sundararaju, D., Tsay, M. H. S. and Subbaraju, G. V., 2006. Biological screening of medicinal plants collected from Eastern Ghaats of India using Artemia salina (Brine shrimp test). Int. J. Appl. Sci. Eng., 4(2):115-125.

[16]. Leelarungrayub, N., Rattanapanone, V., Chanarat, N. and Gebicki, J.M., 2006. Quantitative evaluation of the antioxidant properties of garlic and shallot preparations. Nutrition., 22(3): 266-74.

[17]. Leonard, S.S., Cutler, D., Ding, M., Vallyathan, V., Castranova, V. and Shi, X., 2002. Antioxidant properties of fruit and vegetable juices: More to the story than ascorbic acid". Ann. Clin. Lab. Sci., 32: 193-200.

[18]. McClements J, and Decker E.A., 2000. Lipid oxidation in oil water emulsions: Impact of molecular environment on chemical reactions in heterogeneous food systems. J. Food Sci., 65: 1270-1282

[19]. Morihara, N., Ide, N. and Weiss, N., 2010. Aged garlic extract inhibits CD36 expression in human macrophages via modulation of the PPARc pathway. Phytothera Res., 24(4): 602-608.

[20]. Oyaizu, M., 1986. Studies on products of browning reactions: antioxidant activities of products of browning reaction prepared from glucosamine. J Nutr., 44: 307-315.

[21]. Panpatil, V.V., Tattari, S., Kota, N., Nimgulkar, C. and Polasa, K., 2013. In vitro evaluation on antioxidant and antimicrobial activity of spice extracts of ginger, turmeric and garlic. Journal of Pharmacognosy and Phytochemistry., 2(3): 143-148

[22]. Queiroz, Y.S., Ishimoto, E.Y., Bastos, D.H.M., Sampaio, G.R. and Torres, E.A., 2009. Garlic (Allium sativum L.) and ready-to-eat garlic products: In vitro antioxidant activity. Food Chem., 115(1): 371-374.

[23]. Ruch, R. J., Cheng, S. J. and Klaunig, J. E., 1989. Carcinogenesis, Rely. Chim. Acta., 10, 1003-1008.

[24]. Ruger, C.W., Klinker, E.J. and Hammond, E.G. 2002. Abilities of some antioxidants to stabilize soybean oil in industrial use conditions. J. Am. Oil Chem. Soc., 79(7): 733-736.

[25]. Sagar, B.K. and Singh, R.P. 2011. Genesis and development of DPPH method of antioxidant assay. J Food Sci Technol., 48(4):412422 .

[26]. Sang, G.K., S.Y. Nam, H.C. Chung, S.Y. Hongand and K.H. Jung., 1995. Enhanced effectiveness of dimethyl-4,4,11-dimethoxy$5,6,51,61$,-dimethylene dioxybiphenyl-2,21-dicarboxylate in combination with garlic oil against experimental hepatic injury in rats and mice. J. Pharm. Pharmacol.,47:678-682.

[27]. Singh, T. U., Kumar, D., Tanden, S. K. and Mishra, S. K., 2009. Inhibitory Effect of Essential Oil on Allium sativumand Piper longumon Spontaneous Muscular Activity of Liver Fluke, Fasciola gigantica. Exp. Parasitol., 123:302-308.

[28]. Ullah, J., Hamayoun, M., Ahmed T., Ayub, M. and Zarafullah, M., 2003. Effect of light,natural and synthetic antioxidants on edible oils and fats. Asian J. Plant Sci., 2(17-24): 1192-1194.

[29]. Wangcharoen, W. and Morasuk, W. 2007. Antioxidant capacity and phenolic content of some Thai culinary plants. Maejo Int. J. Sci. Technol., 1: 100-106.

[30]. Yildirim, A., Mavi, A., Oktay, M., Kara, A. A., Algur, O. F. and Bilaloglu, V. 2000. Comparison of antioxidant and antimicrobial activities of Tilia (Tilia argentea Desf ex DC), sage (Salvia

[31]. triloba L.), and Black tea (Camellia sinensis) extracts. Journal of Agricultural and Food Chemistry., 48(10):5030-5034. 